\title{
Prediction of timber bending strength and in-member cross-sectional stiffness variation on the basis of local wood fibre orientation
}

\author{
Anders Olsson · Jan Oscarsson • Erik Serrano • \\ Bo Källsner · Marie Johansson • Bertil Enquist
}

Received: 29 November 2012/Published online: 21 March 2013

(C) The Author(s) 2013. This article is published with open access at Springerlink.com

\begin{abstract}
Machine strength grading of structural timber is based upon relationships between so called indicating properties (IPs) and bending strength. However, such relationships applied on the market today are rather poor. In this paper, new IPs and a new grading method resulting in more precise strength predictions are presented. The local fibre orientation on face and edge surfaces of wooden boards was identified using high resolution laser scanning. In combination with knowledge regarding basic wood material properties for each investigated board, the grain angle information enabled a calculation of the variation of the local MOE in the longitudinal direction of the boards. By integration over cross-sections along the board, an edgewise bending stiffness profile and a longitudinal stiffness profile, respectively, were calculated. A new IP was defined as the lowest bending stiffness determined along the board. For a sample of 105 boards of Norway spruce of dimension $45 \times 145 \times 3,600 \mathrm{~mm}^{3}$, a coefficient of determination as high as $0.68-0.71$ was achieved between this new IP and bending strength. For the same sample, the coefficient of determination between global MOE, based on the first longitudinal resonance frequency and the board density, and strength was only 0.59 . Furthermore, it is shown that improved accuracy when determining the stiffness profiles of boards will lead to even better predictions of bending strength. The results thus
\end{abstract}

\footnotetext{
A. Olsson $(\bowtie) \cdot$ E. Serrano - B. Källsner · M. Johansson .

B. Enquist

Faculty of Technology, Linnaeus University,

35195 Växjö, Sweden

e-mail: anders.olsson@lnu.se

J. Oscarsson

SP Technical Research Institute of Sweden,

Vidéum Science Park, 35196 Växjö, Sweden
}

motivate both an industrial implementation of the suggested method and further research aiming at more accurately determined board stiffness profiles.

\section{Bestimmung der Biegefestigkeit von Schnittholz und der Variation der Biegesteifigkeit in Brettlängsrichtung in Abhängigkeit des lokalen Faserverlaufs}

Zusammenfassung Maschinelle Festigkeitssortierung von Bauholz basiert auf dem Verhältnis zwischen Sortierparametern, den sogenannten IPs, und der Biegefestigkeit. Allerdings sind die heute gebräuchlichen Parameter eher schwach korreliert. In dieser Studie werden neue Sortierparameter sowie ein neues Sortierverfahren für eine genauere Festigkeitsbestimmung vorgestellt. Der lokale Faserverlauf auf den Schmal- und Breitseiten der Bretter wurde mittels hochauflösendem Laserscanning ermittelt. Bei bekannten generellen Materialeigenschaften eines Brettes konnte anhand der Faserwinkelangaben die Variation des lokalen Elastizitätsmoduls in Längsrichtung dieses Brettes berechnet werden. Durch Integration über Querschnitte entlang des Brettes wurde ein Steifigkeitsprofil für Hochkant-Biegebeanspruchung über die gesamte Brettlänge berechnet. Als neuer Sortierparameter (IP) wurde die niedrigste Biegesteifigkeit entlang des Brettes definiert. An einer Stichprobe aus 105 Fichtenbrettern mit den Abmessungen $45 \times 145 \times 3,600 \mathrm{~mm}^{3}$ wurde für die Beziehung zwischen diesem neuen IP und der Biegefestigkeit ein Bestimmtheitsmaß von 0,68-0,71 ermittelt. Bei derselben Stichprobe ergab sich für die Beziehung zwischen dem globalen Elastizitätsmodul, berechnet aus der Eigenfrequenz einer Längsschwingung und der Brettrohdichte, und der Festigkeit ein Bestimmtheitsmaß von nur 0,59. Des Weiteren wurde gezeigt, dass eine höhere Genauigkeit bei der Bestimmung des Steifigkeitsprofils von Brettern zu 
einer noch besseren Bestimmung der Biegefestigkeit führt. Die Ergebnisse rechtfertigen sowohl eine industrielle Anwendung des vorgestellten Verfahrens als auch weitere Forschungsbemühungen, um die Steifigkeitsprofile von Brettern noch genauer bestimmen zu können.

\section{List of symbols}

\begin{tabular}{|c|c|}
\hline$\sigma_{m}$ & Bending strength \\
\hline$E_{m}$ & $\begin{array}{l}\text { Local MOE based on measured deflections in } \\
\text { static bending }\end{array}$ \\
\hline$E_{m, g}$ & $\begin{array}{l}\text { Global MOE based on measured deflections in } \\
\text { static bending }\end{array}$ \\
\hline & Board (average) density \\
\hline$f_{a 1}$ & $\begin{array}{l}\text { Resonance frequency of first longitudinal mode } \\
\text { of vibration }\end{array}$ \\
\hline$E_{a 1}$ & MOE calculated on basis of $f_{a l}$ and $\rho$ \\
\hline$E_{a, \min }$ & $\begin{array}{l}\text { MOE calc. for longitudinal direction in the } \\
\text { weakest section, based on fibre orientation and } \\
f_{a 1}\end{array}$ \\
\hline$E_{b, \min }$ & $\begin{array}{l}\text { MOE calc. for bending of the weakest section, } \\
\text { based on fibre orientation and } f_{a 1}\end{array}$ \\
\hline$E_{b, \min , \delta}$ & $\begin{array}{l}\text { MOE calc. for bending of the weakest } \delta \mathrm{mm} \\
\text { long part of the beam }\end{array}$ \\
\hline$E_{b, \min , \delta, w}$ & $\begin{array}{l}\text { MOE calc. for bending of the weakest } \delta \mathrm{mm} \\
\text { long part of the beam in relation to a weight } \\
\text { function } w\end{array}$ \\
\hline & Coefficient of determination \\
\hline
\end{tabular}

\section{Introduction}

Structural timber is classified into specific strength grades using various methods available on the market. A brief description of the most important ones is given below. However, the statistical relationships being utilized today between the indicating properties (IP) and the target bending strength are rather weak. In commercially available machine strength grading systems, the coefficient of determination, $R^{2}$, between the IPs and the bending strength typically lies in the range of $0.5-0.6$ for Norway spruce. With the most advanced systems known to the market, using a multitude of sensors and measurement principles, values above $R^{2}=0.7$ can be achieved but such systems are rarely used in practice. Improvements of the coefficient of determination between the IPs and the bending strength have a considerable commercial potential as higher accuracy would make it possible to efficiently grade timber into higher strength classes than what can be done today, and a better yield would be achieved in the more common strength classes.

The basic principle for machine strength grading of structural timber is generally to determine a modulus of elasticity (MOE) of a board and to use this property as an IP for prediction of bending strength. Dynamic excitation can, in combination with density and board length, be used to determine a global, longitudinal MOE directly, see e.g. Larsson (1997). This method is frequently applied using relatively inexpensive machines. It could also be utilized without determination of the actual board density. In such cases, an average density of the graded wood species is used.

A literature review carried out by Olsson et al. (2011) showed that the bending stiffness correlates better with bending strength than what the longitudinal stiffness does. Olsson et al. (2011) also showed that a set of resonance frequencies corresponding to higher modes of vibration can be used for assessing the homogeneity of a board. A measure of inhomogeneity (MOI), corresponding to the variation of stiffness along a board, was suggested as a complementary IP, i.e., to be used in combination with the MOE, for prediction of bending strength.

Flatwise bending machines have been used since the 1960s and are still available on the market. Over a span of about one metre, and moving along the board, the bending stiffness is measured and on this basis a MOE valid for flatwise bending representing a certain part of the board is calculated. Thus, such machines give some information regarding the stiffness variation along the board.

The sizes and locations of knots can be detected with rather high precision using X-ray techniques. The benefit of such detection is underlined by the fact that fracture testing of a sample of about 1,000 pieces of timber has shown that more than $90 \%$ of the failures were caused by knots (Johansson 2003). Schajer (2001) was able to make better predictions using an X-ray technique than what could be done using a bending machine in a comparative study. There are grading machines on the market today that combine X-ray techniques with either flat-wise bending or measurement of the dynamic longitudinal stiffness. The information added by the X-ray technique compared to the other techniques is a high resolution in measuring the variation of the density within a board.

The orientation of wood fibres in timber has a large effect on stiffness and strength and there are techniques to identify the fibre orientation locally on the surface or within wooden members. An early attempt to utilize such information for strength grading purposes was presented by Bechtel and Allen (1987). The fact that the dielectric constant is higher in the fibre direction or actually in the direction of fibres projected on a surface than across the fibres was utilized. Fibre angles were identified over the two face surfaces of boards and it was shown that the detected grain field could be used for identifying knots. Three different methods aiming at actually calculating the crack path and the tensile strength of boards were also 
suggested. The methods were based on the Hankinson formula by which the local tensile strength in the direction of the board was expressed as a function of the tensile strength in the fibre direction and the local fibre angle. For a small sample consisting of 24 specimens it was shown that a coefficient of determination between calculated and true tensile strength exceeding 0.8 could be reached. However, the coefficient of determination between global MOE and true tensile strength was for the same sample 0.77 , which is very high compared with what has been presented in other studies and also compared with what is reached in grading utilizing global MOE as indicating property to strength. Two possible explanations for the high $R^{2}$ values were offered. First, the tensile test was carried out over a short span $(70 \mathrm{~cm})$ and, second, usual statistical procedures for material sampling were not followed. Recently Moore and Baldwin (2011) discussed the method suggested by Bechtel and Allen and concluded that nowadays it is possible to identify the grain angle field on the basis of the dielectric constant in a speed corresponding to the production speed at sawmills. They also suggested an improved version of one of the methods suggested by Bechtel and Allan, but it was only verified on a very small sample consisting of nine planed fir boards two of which had to be excluded because of twist causing difficulties when applying the dielectric method.

Laser techniques utilizing the so-called tracheid effect for detecting fibre orientation are available and have been implemented in high speed, high resolution wood-scanners already on the market. However, the technique is not yet utilized for strength grading purposes in a sophisticated way. Petersson (2010) showed that size and location of knots can be determined on the basis of the grain-angle distribution detected using this technique. In addition, he presented research which was aimed at accurately predicting the stiffness on the basis of end scanning, including information about pith location and annual ring width.

In a study by Jehl et al. (2011), the influence of fibre angles on the prediction of both MOE and tensile strength was evaluated. The fibre angle fields were examined over the face surfaces of 350 boards. Also the diving angle, i.e. the angle between the board surface and the wood fibres, was evaluated by examining the shape of the elliptic laser dot, which due to the tracheid effect is stretched in the direction of the projected fibre angle. The authors claim that the diving angle can be determined in this way but they also say that the results achieved are rather uncertain. Furthermore, it was assumed that the MOE is an affine function of the density. Thus, a map of the local board density, averaged through the thickness of each board, was obtained from an optical scanner equipped with an X-ray source. From such maps, the fraction of the thickness occupied by a knot was computed on pixel level and the corresponding clear wood area ratio (CWAR) was determined. To take the effect of fibre angle fields into account, local CWAR values were modified using Hankinson's formula. Finally, a board's MOE was determined either from axial dynamic excitation or as the product of modified CWAR and the clear wood's MOE. The tensile strength was similarly estimated as the product of modified CWAR and clear wood tensile strength. By application of the described method it was possible to predict tension strength with very high accuracy, at best with a coefficient of determination of 0.78 .

As previous research has pointed out, high resolution information regarding fibre angles has a very interesting potential for strength grading purposes. However, whereas the research referred to above is based mainly upon empirical relationships, a theoretically sound base for the relationship between wood material properties, fibre orientation in timber and local MOE in the direction of the board is presented in this paper. A suitable IP to bending strength is also defined and the potential for further improvements of the concept of utilizing local stiffness for strength grading purposes is evaluated. A patent application has recently been filed for an invention corresponding to the method presented herein.

\section{Sampling of material for evaluation}

The sampling of timber for the investigation took place in Långasjö, Sweden, on December 11-12, 2007, at a sawmill owned by the company Södra Timber. The timber consisted of sawn boards of Norway spruce (Picea abies) of nominal dimensions $50 \times 150 \mathrm{~mm}^{2}$ and of length $3,900 \mathrm{~mm}$ or $4,500 \mathrm{~mm}$. In the sampling it was aimed for a sample with large variation in strength. Thus, boards with high and low expected strength were included. For this purpose a grading machine of type Dynagrade ${ }^{\circledR}$ was employed with settings for grading of timber to be used for roof trusses (strength class TR26) on the UK market. Both boards fulfilling (61 pieces) and boards not fulfilling the requirements (44 pieces) were selected for further investigation. A visual assessment was performed in order to identify the weakest section of each board according to instructions in the European standard EN 384 (CEN 2010a). This standard prescribes that the weakest section should be located in the maximum bending moment zone, i.e. between the two point loads in a four point bending test, and that the tension edge shall be selected at random after the weakest section has been chosen.

All the boards were planed to dimension $45 \times 145 \mathrm{~mm}^{2}$ immediately after selection. Then the boards were cut to a length of 3,600 $\mathrm{mm}$ and placed in a climate room holding a temperature of $20{ }^{\circ} \mathrm{C}$ and $65 \%$ relative humidity (RH). 
Small pieces of wood were also saved and stored in the climate room for assessment of the moisture content.

\section{Methods and measurements}

The research involves laboratory testing including laser scanning, dynamic excitation and static loading. Quantities measured in the laboratory were the weight and dimensions of the boards, high resolution fibre orientation fields on the surfaces of the boards, resonance frequencies corresponding to longitudinal modes of vibration, static edgewise bending stiffness (determined in two different ways, giving a local and a global measure, respectively) and the bending strength. The arrangements and performance of the scanning and dynamic and static tests are described below.

In addition to the laboratory work, the research also involves analytical and numerical calculations and common regression analysis using the software Matlab ${ }^{\circledR}$.

\subsection{Scanning for detection of fibre angles on surfaces}

A WoodEye scanner (from Innovativ Vision AB) equipped with four sets of multi-sensor cameras, dot and line lasers and conveyor belts for feeding boards in the longitudinal direction through the scanner was used for face and edge scanning. Figure 1 shows the WoodEye-scanner (left) and an overview of the WoodEye system with lasers, light and multi-sensor cameras (right). The notation "IN" marks the cross section of a scanned board. The laser scanning makes use of the so-called tracheid effect where one of the principal axes of the light intensity distribution around a laser dot is oriented in the direction of the wood fibres (Nyström 2003). This provides a practical method for measuring variations in grain angle on a wood surface. Figure 2 shows
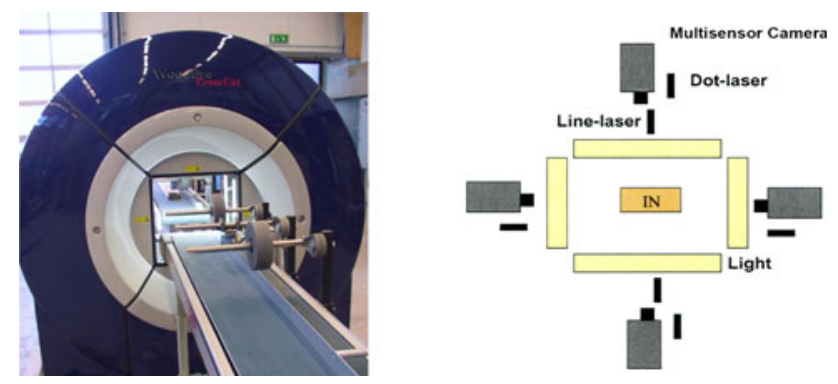

Fig. 1 WoodEye-scanner (left) and overview of the WoodEye system with lasers, light and multisensor cameras (right). The notation "IN" marks the cross-section of a scanned board [Images originate from Petersson (2010).]

Abb. 1 WoodEye-Scanner (links) und Darstellung des WoodEyeSystems mit Lasern, Licht und Multisensorkameras (rechts). „IN“gibt den Querschnitt des gescannten Brettes an (aus Petersson 2010) a piece of wood including a knot (left), an image showing how the light from the dot lasers spread on the wood surface (middle) and the fibre orientation on the wood surface (right) calculated by identifying the major principal axis of each light spot using image analysis. Within knots, where the shape of the light spots is close to circular, the calculation of the fibre direction becomes uncertain. This is indicated in Fig. 2 (right) by the dotted lines drawn for the calculated fibre orientations corresponding to such laser dots.

The resolution employed for scanning of the boards, i.e. the distance between laser dots on the surfaces, was $0.8 \mathrm{~mm}$ in the longitudinal direction of the board and $3.6 \mathrm{~mm}$ in the lateral board direction. It should be noted that the grain angle detected actually represents the fibre orientation projected on the surface. Consequently, the so called diving angle is not assessed here.

\subsection{Determination of dynamic stiffness}

Determination of the lowest longitudinal resonance frequency of each board, which in combination with the board density is used for calculating an average board MOE, was performed using an MTG hand-held timber grader. The MTG grader is a wireless measuring instrument for strength grading of structural timber (Brookhuis MicroElectronics 2009). It is approved as machine grading system with settings listed in EN 14081-4 (CEN 2009). The frequency measurement is carried out simultaneously as the board is supported by a balance from which the weight is determined. The resonance frequencies of the boards included in this study were also assessed using a more advanced laboratory setup in which free-free boundary conditions were resembled by suspending the boards in rubber bands. In this test setup the board was hit with an impulse hammer at one end of the board and the vibration content was measured using an accelerometer fastened at the other end. The coefficient of determination between the lowest longitudinal resonance frequencies measured using the two different sets of equipment was as high as $R^{2}=0.999$.

\subsection{Static four-point bending test}

The local and global static bending stiffness and the bending strength of the boards were determined using a four point bending test according to the European standard EN 408 (CEN 2010b). The total span was 2,610 mm long (corresponding to eighteen times the depth of the board) and the two point loads were applied $870 \mathrm{~mm}$ apart, each of them $870 \mathrm{~mm}$ from the nearest support. For such a load case, the mid-span is subjected to a constant bending moment and no shear force. The predicted weakest part of 

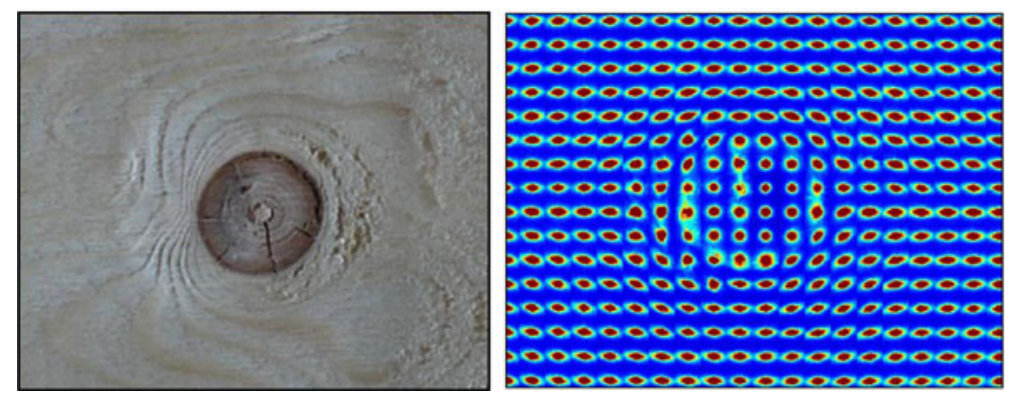

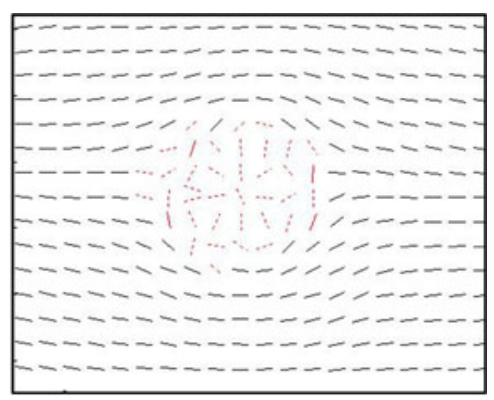

Abb. 2 Holzprobe mit Ast (links); Bild, das zeigt, wie sich das Licht der Punktlaser auf der Holzoberfläche ausbreitet (Mitte); Faserverlauf auf der Holzoberfläche (rechts) berechnet mittels Bildanalyse auf Basis der bestimmten Hauptachse jedes Lichtpunktes (Petersson (2010))
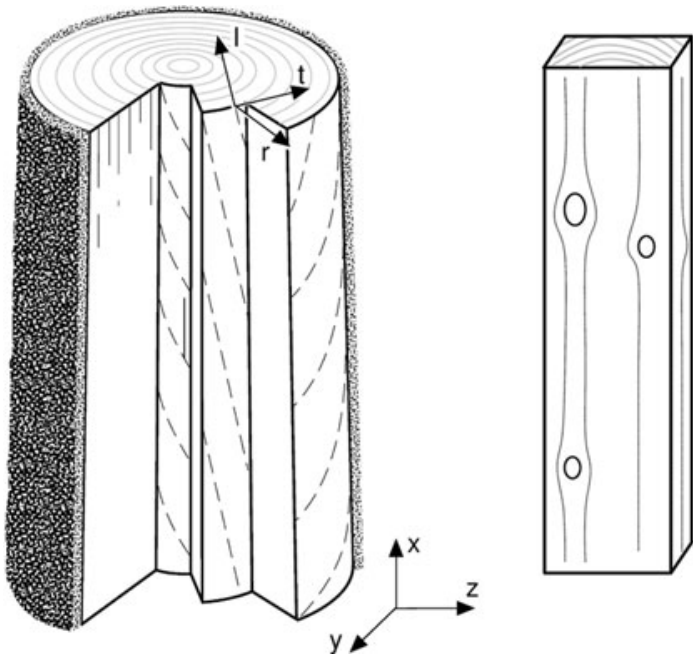

each board, selected by means of visual inspection, was located within the zone with constant bending moment, i.e. between the two point loads, and was randomly located with respect to the position of the tension side of the board.

\section{Calculation of stiffness on the basis of fibre angles}

It is well known that wood is a strongly orthotropic material having very high stiffness and strength in the fibre direction but low stiffness and strength in other directions. In a stem or wooden board, most fibres are close to parallel with the longitudinal stem or board direction, but also small deviations in fibre direction have a significant effect on the board properties. Locally, in particular within and in the close surrounding of knots, the fibre direction may deviate strongly from the longitudinal direction of the stem or board, see Fig. 2 (right), and this is crucial for the structural properties of timber.

Figure 3 shows a drawing of a part of a stem and a drawing of a board that could have been cut out from it. Two different coordinate systems are displayed, one global with axes parallel to the sides of the board and one local relating to the main directions of the wood material in a position in the stem. From an engineering point of view one needs to describe the structural properties in relation to a coordinate system where one axis $(\mathrm{x})$ is parallel to the longitudinal direction of the board and the other two axes ( $\mathrm{y}$ and $\mathrm{z}$ ) are oriented parallel to the thickness direction and depth direction, respectively. Knowing the fibre orientation locally in relation to the board direction, material transformations can be carried out giving the local material properties corresponding to the principal directions of the board, i.e. the global coordinate system. Assuming that $(\mathbf{l}, \mathbf{r}, \mathbf{t})$ and $(\mathbf{i}, \mathbf{j}, \mathbf{k})$ are the unit vectors along the 1-r-t system and the $x-y-z$ system, respectively, one can write
Fig. 3 Drawing of a part of a stem and of a board that could have been cut out from it. Two different coordinate systems are displayed, one global with axes parallel to the sides of the board and one local relating to the main directions of the wood material in a position in the stem [The left drawing originates from Ormarsson (1999).]

Abb. 3 Teil eines Stammes und ein daraus entnommenes Brett. Zwei verschiedene Koordinatensysteme sind dargestellt, ein globales mit Achsen parallel zu den Seiten des Brettes sowie ein lokales entsprechend den Hauptrichtungen der Holzstruktur im Stamm (linke Zeichnung aus Ormarsson 1999)

$$
\left[\begin{array}{l}
\mathbf{l} \\
\mathbf{r} \\
\mathbf{t}
\end{array}\right]=\mathbf{A}^{\mathbf{T}}\left[\begin{array}{l}
\mathbf{i} \\
\mathbf{j} \\
\mathbf{k}
\end{array}\right]
$$

where

$\mathbf{A}=\left[\begin{array}{lll}a_{l}^{x} & a_{r}^{x} & a_{t}^{x} \\ a_{l}^{y} & a_{r}^{y} & a_{t}^{y} \\ a_{l}^{z} & a_{r}^{z} & a_{t}^{z}\end{array}\right]$

where $a$ denotes cosine for the two axes indicated by the subscript and the superscript, respectively, for instance, $a_{l}^{x}$ denotes cosine for the angle between the 1 - and $\mathrm{x}$-axes. 
The wood material properties relating to local directions can be stored in the compliance matrix $\overline{\mathbf{C}}$ as (the symbol is used in notations whenever a quantity is expressed in the local coordinate system and omitted when the quantity is expressed in the global coordinate system)

$$
\overline{\mathbf{C}}=\left[\begin{array}{cccccc}
\frac{1}{E_{l}} & -\frac{v_{r l}}{E_{r}} & -\frac{v_{l l}}{E_{t}} & 0 & 0 & 0 \\
-\frac{v_{l r}}{E_{l}} & \frac{1}{E_{r}} & -\frac{v_{r t}}{E_{t}} & 0 & 0 & 0 \\
-\frac{v_{l t}}{E_{l}} & -\frac{v_{r t}}{E_{r}} & \frac{1}{E_{t}} & 0 & 0 & 0 \\
0 & 0 & 0 & \frac{1}{G_{l r}} & 0 & 0 \\
0 & 0 & 0 & 0 & \frac{1}{G_{l t}} & 0 \\
0 & 0 & 0 & 0 & 0 & \frac{1}{G_{r t}}
\end{array}\right]
$$

where $E_{l}, E_{r}, E_{t}$ are the moduli of elasticity in the orthotropic directions, $G_{l r}, G_{l t}, G_{r t}$ are the shear moduli in the respective orthotropic planes, and the parameters $v_{l r}, v_{r l}, v_{l t}$, $v_{t l}, v_{r t}$ and $v_{t r}$ are Poisson's ratios. Note that the relations $v_{r l}=\mathrm{E}_{r} / \mathrm{E}_{l} \times v_{l r}, \quad v_{t l}=\mathrm{E}_{t} / \mathrm{E}_{l} \times v_{l t}$ and $v_{t r}=\mathrm{E}_{t} / \mathrm{E}_{r} \times v_{r t}$ hold which means that $\overline{\mathbf{C}}$ only contains nine independent material parameters.

The material matrix $\overline{\mathbf{D}}=\overline{\mathbf{C}}^{-1}$ (relating to the l-r-t system, i.e. the local coordinate system) may be used to express a linear elastic constitutive relation between stresses and strains as

$\overline{\boldsymbol{\sigma}}=\mathbf{D} \varepsilon$

where strain and stress components are stored in $\overline{\boldsymbol{\varepsilon}}$ and $\overline{\boldsymbol{\sigma}}$, respectively, as $\overline{\boldsymbol{\varepsilon}}=\left[\begin{array}{llllll}\varepsilon_{l} & \varepsilon_{r} & \varepsilon_{t} & \gamma_{l r} & \gamma_{l t} & \gamma_{r t}\end{array}\right]^{\mathrm{T}}$ and $\overline{\boldsymbol{\sigma}}=\left[\begin{array}{llllll}\sigma_{l} & \sigma_{r} & \sigma_{t} & \tau_{l r} & \tau_{l t} & \tau_{r t}\end{array}\right]^{\mathrm{T}}$. Strains and stresses may be transformed between the l-r-t system and the x-y$\mathrm{z}$ system using a transformation matrix $\mathbf{G}$ as

$\overline{\boldsymbol{\varepsilon}}=\mathbf{G} \varepsilon$

and

$\boldsymbol{\sigma}=\mathbf{G}^{\mathbf{T}} \overline{\boldsymbol{\sigma}}$

respectively, where the transformation matrix

$\mathbf{G}=\left[\begin{array}{cccccc}a_{l}^{x} a_{l}^{x} & a_{l}^{y} a_{l}^{y} & a_{l}^{z} a_{l}^{z} & a_{l}^{x} a_{l}^{y} & a_{l}^{z} a_{l}^{x} & a_{l}^{y} a_{l}^{z} \\ a_{r}^{x} a_{r}^{x} & a_{r}^{y} a_{r}^{y} & a_{r}^{z} a_{r}^{z} & a_{r}^{x} a_{r}^{y} & a_{r}^{z} a_{r}^{x} & a_{r}^{y} a_{r}^{z} \\ a_{t}^{x} a_{t}^{x} & a_{t}^{y} a_{t}^{y} & a_{t}^{z} a_{t}^{z} & a_{t}^{x} a_{t}^{y} & a_{t}^{z} a_{t}^{x} & a_{t}^{y} a_{t}^{z} \\ 2 a_{l}^{x} a_{r}^{x} & 2 a_{l}^{y} a_{r}^{y} & 2 a_{l}^{z} a_{r}^{z} & a_{l}^{x} a_{r}^{y}+a_{l}^{y} a_{r}^{x} & a_{l}^{z} a_{r}^{x}+a_{l}^{x} a_{r}^{z} & a_{l}^{y} a_{r}^{z}+a_{l}^{z} a_{r}^{y} \\ 2 a_{t}^{x} a_{l}^{x} & 2 a_{t}^{y} a_{l}^{y} & 2 a_{t}^{z} a_{l}^{z} & a_{t}^{x} a_{l}^{y}+a_{t}^{y} a_{l}^{x} & a_{t}^{z} a_{l}^{x}+a_{t}^{x} a_{l}^{z} & a_{t}^{y} a_{l}^{z}+a_{t}^{z} a_{l}^{y} \\ 2 a_{r}^{x} a_{t}^{x} & 2 a_{r}^{y} a_{t}^{y} & 2 a_{r}^{z} a_{t}^{z} & a_{r}^{x} a_{t}^{y}+a_{r}^{y} a_{t}^{x} & a_{r}^{z} a_{t}^{x}+a_{r}^{x} a_{t}^{z} & a_{r}^{y} a_{t}^{z}+a_{r}^{z} a_{t}^{y}\end{array}\right]$

is based on the components of $\mathbf{A}$ defined in Eq. (2) (Ormarsson 1999). By premultiplication of Eq. (4) by $\mathbf{G}^{\mathbf{T}}$ and considering Eqs. (5-6) it follows that the material matrix relating to the $\mathrm{x}-\mathrm{y}-\mathrm{z}$ system can be expressed as

$\mathbf{D}=\mathbf{G}^{\mathbf{T}} \overline{\mathbf{D}} \mathbf{G}$

Of particular interest for the following is that $c_{1,1}^{-1}$, i.e. the inverse of the component stored in the first row and first column of the globally oriented compliance matrix $\mathbf{C}=\mathbf{D}^{-1}$, is now equal to $E_{x}(x, y, z)$, i.e. the local MOE valid in the longitudinal direction of the board.

\subsection{Modulus of elasticity calculated on board surfaces}

The description above concerning how to calculate local MOE in the longitudinal board direction is presented in general terms. In practice, however, certain assumptions have to be made as the knowledge regarding true fibre angle orientation is not complete. It is now assumed that the projected fibre angles on the lateral board surfaces (a lateral board surface is a surface with a normal direction perpendicular to the longitudinal direction of the board) detected by means of scanning represent the true, threedimensional fibre orientation on these surfaces. It is also assumed that the normal direction of each lateral board surface is parallel with the radial direction of the wood material, i.e. that each lateral surface is oriented in the longitudinal-tangential plane. If the basic wood material parameters, i.e. the parameters involved in the locally oriented compliance matrix $\overline{\mathbf{C}}$ (Eq. 3 above), are known the MOE on the lateral board surfaces in the longitudinal board direction can be calculated. The issue of how to determine the basic wood material parameters valid for an individual board is addressed in a separate section below, but it is suitable for the purposes of this study to show, already at this stage, an example of calculation results, with high spatial resolution, regarding MOE on lateral board surfaces. Figure 4 (left) shows photographs of all four sides of one board (denoted board number 74) and MOE in longitudinal board direction over the board surfaces (right) calculated on the basis of the local fibre angles (or rather on their projections on the wood surface). The $\mathrm{x}$-axis starts at the root end of the board. Red colour indicates a high MOE, found in areas where the orientation of the wood fibres coincide with the longitudinal direction of the board, and blue colour indicates a particularly low MOE corresponding to a local fibre direction diverging substantially from the longitudinal board direction. Note that areas occupied by knots typically have a fibre orientation substantially diverging from the longitudinal board direction. The absolute level of the MOE in the individual board depends on the basic material parameters, of which the MOE in the fibre direction is the most important one. The centre parts of Fig. 4 shows photographs, projected fibre angle field and calculated MOE in the longitudinal board direction of a small part of the board. The topmost centre part of Fig. 4 shows an enlargement of the fibre angle field at a single large knot in the board. 


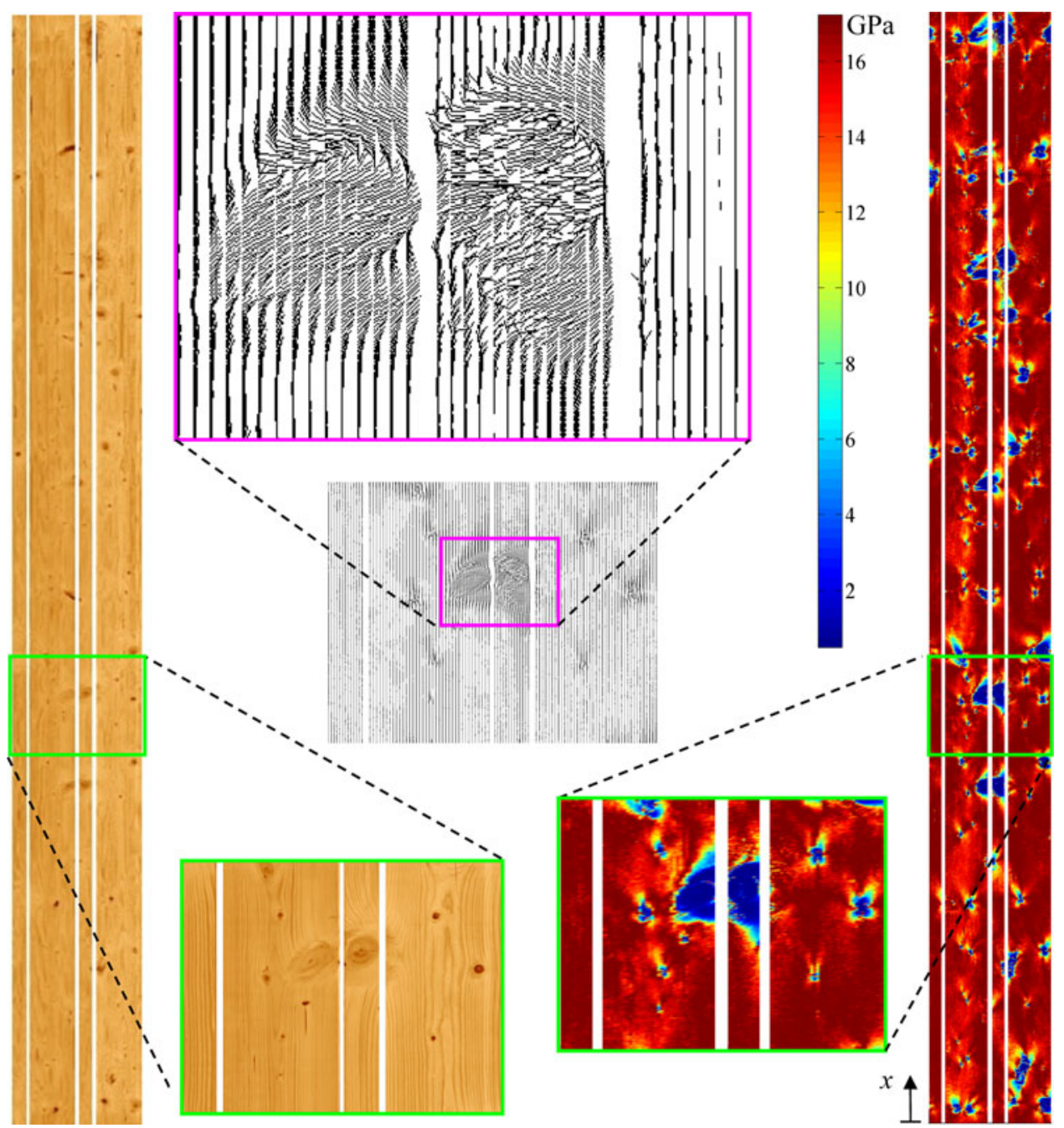

Fig. 4 Photographs of all four sides of one board (left) and calculated MOE in longitudinal board direction over the entire board surface (right). The $\mathrm{x}$-axis starts at the root end of the board. Red colour indicates a high MOE, found in areas where the orientation of the wood fibres coincide with the longitudinal direction of the board, and blue colour indicates a particularly low MOE corresponding to a local fibre direction diverging substantially from the longitudinal board direction. The centre parts show photographs, projected fibre angle field and calculated MOE in a small part of the board. The topmost centre part shows an enlargement of the projected fibre angle field at a single large knot in the board

\section{Integration of cross-sectional stiffness properties}

Now follows a more general description and it is assumed that the MOE valid in the longitudinal direction of the board is known in every position within it, i.e. $E_{x}=E_{x}(x, y, z)$ is known for $0 \leq x \leq L,-t / 2 \leq y \leq t / 2$ and $-d / 2 \leq z \leq d / 2$, where $L, t$ and $d$ is the length, thickness and depth of the board, respectively. Furthermore, a coordinate system with its origin at one end of the board and in the geometrical centre of the cross-
Abb. 4 Aufnahmen aller vier Brettseiten (links) und berechneter Elastizitätsmodul in Brettlängsrichtung über die gesamte Brettfläche (rechts). Die x-Achse beginnt am Fußende des Brettes. Rote Farbe gibt einen hohen E-Modul an in Bereichen, in denen der Faserverlauf mit der Brettlängsrichtung übereinstimmt, und blaue Farbe zeigt einen besonders niedrigen E-Modul bei einem lokalen Faserverlauf, der wesentlich von der Brettlängsrichtung abweicht. In der Mitte sind ein projiziertes Faserwinkelfeld und der E-Modul-Verlauf eines kleinen Brettabschnitts abgebildet. Ganz oben in der Mitte ist eine Vergrößerung des projizierten Faserwinkelfeldes im Bereich eines großen Astes zu sehen

section is introduced. Considering the wooden board as a beam, the position of the neutral axis (i.e. the position $(y, z)$ within the board cross-section where, according to traditional beam theory, zero normal stress is obtai ned when the beam is exposed to pure bending around the $y$-axis and the $z$-axis, respectively) can be calculated as

$$
\bar{y}(x)=\frac{\iint E_{x} \cdot y d y d z}{\iint E_{x} d y d z}
$$


and

$$
\bar{z}(x)=\frac{\iint E_{x} \cdot z d y d z}{\iint E_{x} d y d z}
$$

respectively. The bending stiffness along the beam with respect to bending around the $y$ - and $z$-axis can then be calculated as

$E I_{y}(x)=\iint E_{x} \cdot(z-\bar{z})^{2} d y d z$

and

$E I_{z}(x)=\iint E_{x} \cdot(y-\bar{y})^{2} d y d z$

respectively (One may note that these axes are not actually principal axes.). The longitudinal board stiffness can be calculated as

$E A(x)=\iint E_{x} d y d z$

5.1 Calculation of cross-sectional stiffness properties under certain assumptions

Knowing the spatial distribution of the material orientation and the stiffness properties of the material everywhere within the board it is thus possible to calculate the stiffness in the longitudinal direction of the board and, by integration, to calculate the stiffness properties on the cross-sectional level. However, with limited information regarding the material orientation within the boards, certain assumptions have to be made before the cross-sectional stiffness properties can actually be calculated. In addition to the assumptions declared above when calculating the MOE in the longitudinal board direction on the lateral board surfaces it is also assumed that the detected fibre directions are representative for the material to a certain depth in the board in direction perpendicular to the surfaces. Figure 5 illustrates a suggested way to represent the fibre angle field and MOE within the board. The drawing on the left shows the cross-section divided into small strips, each with one side coinciding with one side of the board. One such strip is highlighted in grey. The drawing on the right shows a small segment of length $d x$ in the longitudinal direction of the board and projected fibre angles, $\varphi$, on one surface of this segment. Fibre angles are detected with a certain resolution which is illustrated by the size of the strips drawn. The MOE in the longitudinal direction of the board is calculated for each fibre angle sampling point and this MOE is considered as being representative for a certain wood volume, i.e. the volume given by the area $d A$ times the distance $d x$, cf. Fig. 5. A numerical integration is then executed in accordance with Eqs. (9-13) giving, as functions of $x$, the position of the neutral axis, the cross-sectional bending stiffness in the strong and weak direction of the board, respectively, and the longitudinal board stiffness. The distance $a$ shown in Fig. 5 is set to

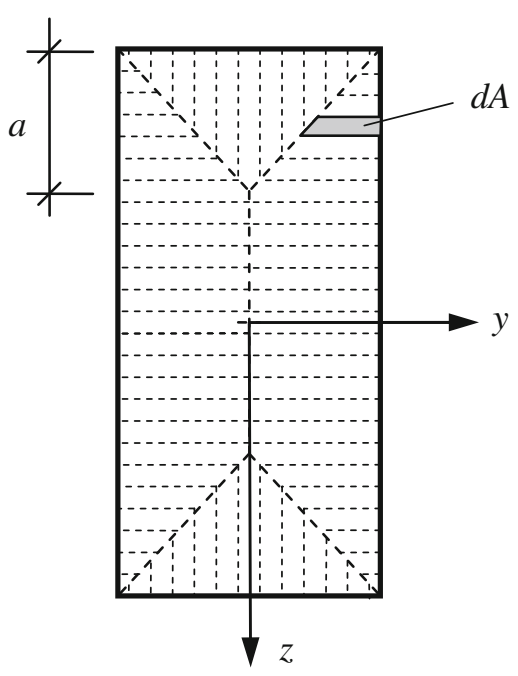

Fig. 5 A suggested way to represent the fibre angle field and MOE within the board. The drawing on the left shows the cross-section divided into small strips, each with one side coinciding with one side of the board. One strip is highlighted in grey. The drawing on the right shows a small segment of length $d x$ in the longitudinal direction of the board and detected fibre angles on one surface of this segment

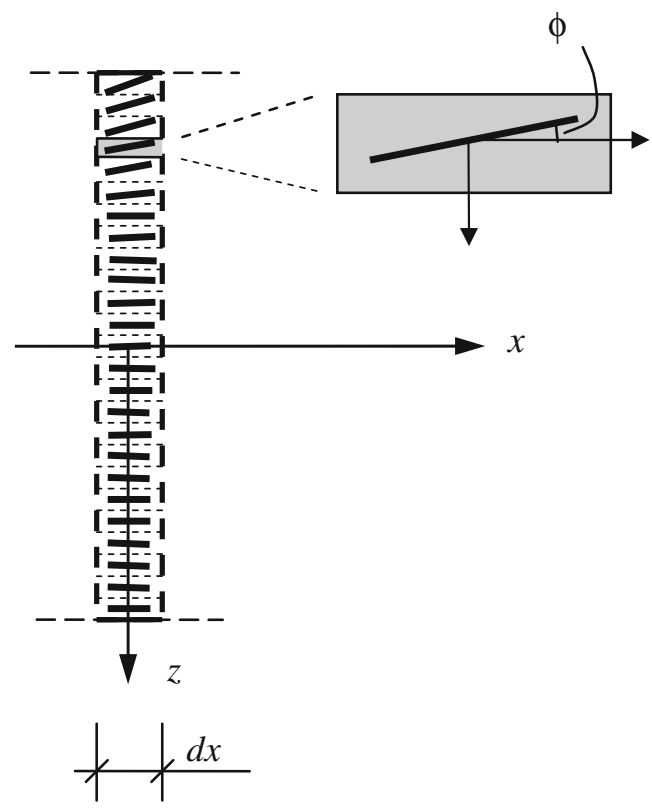

Abb. 5 Vorschlag zur Darstellung des Faserwinkelfeldes und des E-Moduls in einem Brett. Links: Brettquerschnitt unterteilt in kleine Streifen, ausgerichtet zu den Brettseiten. Ein Streifen ist grau markiert. Rechts: Kleiner Abschnitt in Brettlängsrichtung $d x$ mit ermitteltem Faserwinkel auf einer Brettseite dieses Abschnittes 
$35 \mathrm{~mm}$ when performing the integration herein. More advanced integration schemes, possibly taking into account pith location and the general pattern for three dimensional grain flows around knots would be an interesting subject for further research.

Examples of graphs displaying the position of the neutral axis in the $x y$-plane (in relation to the geometric centre axis) and the edgewise bending stiffness profile, respectively, are shown in Fig. 6 for one board, here denoted board number 74 (the same board is shown in Fig. 4). The calculations are performed using the assumptions and integration scheme described above and results are shown for two different resolutions in the board direction. The two diagrams at the top of Fig. 6 show graphs corresponding to the maximum resolution achieved from scanning, i.e. with values determined at a distance of $0.8 \mathrm{~mm}$ apart along the board. The two diagrams at the bottom show graphs where the value at each position (i.e. at each $\mathrm{x}$ coordinate) is the average value of the surrounding $80 \mathrm{~mm}$ along the board, i.e. along $40 \mathrm{~mm}$ on each side of the $x$-coordinate in question. The root end of the board has $x$-coordinate equal to zero.

\section{Material parameters and calibration of cross- sectional stiffness properties}

The procedure described above for calculating cross-sectional stiffness properties along boards requires that the wood material properties are known, i.e. that they are known in relation to a local coordinate system with axes coinciding with the longitudinal, radial and tangential directions, respectively. Though average values for material properties valid for different species can be found in literature, the properties may differ substantially between boards originating from different trees and stands. Even within a tree, some properties may vary considerably, particularly in the direction from pith to bark (e.g. Wormuth 1993). The modulus of elasticity in the fibre direction, $E_{l}$, is by far the material parameter with the highest influence on the MOE in the board direction. Therefore it is important to assess a value for this parameter valid for each single board. Table 1 shows nominal values, $E_{l, 0}, E_{r, O}, E_{t, O}$, $G_{l r, O}, G_{l t, O}, \quad G_{r t, O}, \quad v_{l r}, \quad v_{l t}$, and $v_{r t}$, originating from Dinwoodie (2000), for the wood material parameters used in this study. The material parameters are then adjusted for each individual board by considering an experimentally determined resonance frequency as described below. The parameters are adjusted in such a way that the relations between the different calibrated parameters, $E_{l}, E_{r}, E_{t}, G_{l r}$, $G_{l t}, G_{r t}$, are preserved, i.e. they are identical with the corresponding relations for the nominal parameters. The Poisson's ratios, $v_{l r}, v_{l t}$ and $v_{r t}$ are kept constant. This means that a locally oriented compliance matrix, Eq. (3), determined for a particular board only differs compared to the nominal compliance matrices (i.e., a compliance matrix having nominal values for all material parameters involved) by a constant factor. Variations of material parameters within boards are ignored herein, i.e. the locally oriented compliance matrix valid for a particular board is not a function of position within the board.

As described in a previous section the resonance frequency corresponding to the first longitudinal mode of vibration can be determined experimentally. On the basis of such an experiment, an average MOE valid for the longitudinal direction of the board can be calculated as

$E_{a 1}=4 \cdot \rho \cdot f_{a 1}^{2} \cdot L^{2}$

where $\rho$ is the average board density, $f_{a 1}$ is the measured resonance frequency and $L$ is the board length.

The material parameters representing a particular board should be such that an eigenfrequency analysis on a computational model based on these material parameters should give the same resonance frequency as the one determined experimentally. Therefore a simple one dimensional finite element model of each board is established which resembles the longitudinal stiffness profile calculated using Eq. (13) on the basis of nominal values for material parameters. The stiffness of each finite element in the model represents a short distance, $\Delta x$ (approximately one centimetre), of the total board length and the axial stiffness of the $p$ th element is calculated by averaging the axial stiffness obtained from Eq. (13) over the element length

$k_{p}=\frac{\int_{(p-1) \Delta x}^{p \Delta x} E A(x) d x}{\Delta x^{2}}$

In the FE model the mass of the board is assumed to be uniformly distributed in the longitudinal direction and a resonance frequency denoted $\hat{f}_{a 1}$ is calculated by performing eigenvalue analysis on this FE model. The reason for calculating $\hat{f}_{a 1}$ is thus to compare it with $f_{a 1}$ and to adjust the value employed for material parameters accordingly. Starting with the nominal values for all the material parameters the final values are adjusted in relation to the quota of the two resonance frequencies in square, e.g.

$E_{l}=E_{l, 0} \frac{f_{a 1}^{2}}{\hat{f}_{a 1}^{2}}$

The final board stiffness profiles, $E A(x), E I_{y}(x)$ and $E I_{z}$ $(x)$ that may be utilized for strength grading purposes are thus based on material parameters assessed individually for each board after calibration to an experimentally determined resonance frequency. This means, of course, that the calculation results displayed in Figs. 4 and 6 are 
Fig. 6 Calculated position of neutral axis and local bending stiffness of board number 74 . The two diagrams at the top show graphs corresponding to maximum resolution in the board direction, i.e. with values determined at a distance of $0.8 \mathrm{~mm}$ apart along the board. The two diagrams at the bottom show graphs where the value at each position is the average value of the surrounding $80 \mathrm{~mm}$ along the board

Abb. 6 Berechnete Lage der neutralen Achse und lokale Biegesteifigkeit des Brettes Nummer 74. Die beiden oberen Diagramme zeigen Graphen mit der maximalen Auflösung in Brettlängsrichtung, d.h. mit Werten, die in einem Abstand von $0,8 \mathrm{~mm}$ bestimmt wurden. Die beiden unteren Diagramme zeigen Graphen, bei denen die Werte über eine Länge von $80 \mathrm{~mm}$ gemittelt wurden
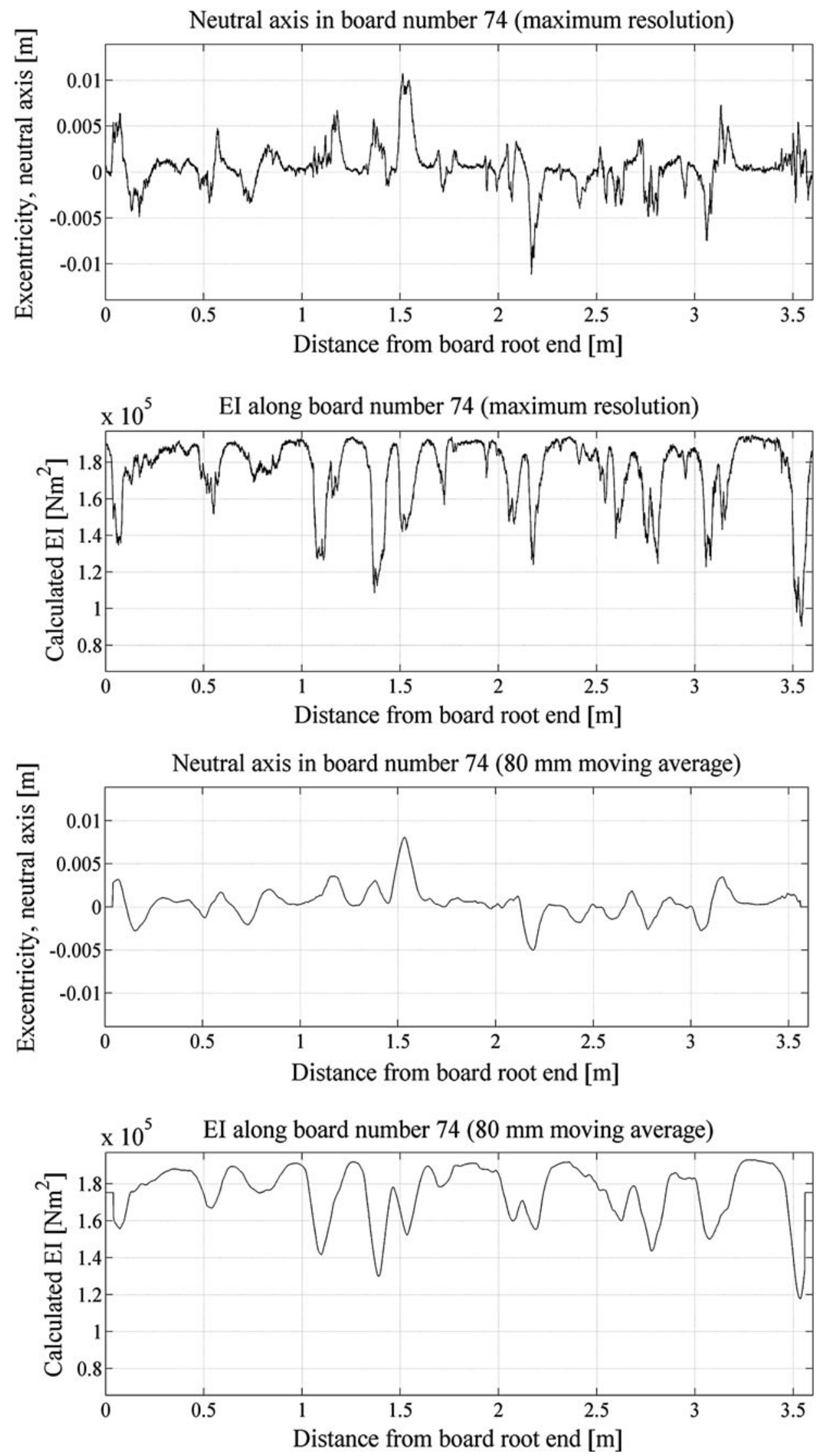
Table 1 Nominal material parameters employed (Norway spruce) Tab. 1 Verwendete Materialkenngrößen (Fichtenholz)

\begin{tabular}{ll}
\hline$E_{l, O}$ & $10,700 \mathrm{MPa}$ \\
$E_{r, O}$ & $710 \mathrm{MPa}$ \\
$E_{t, O}$ & $430 \mathrm{MPa}$ \\
$G_{l r, O}$ & $500 \mathrm{MPa}$ \\
$G_{l t, O}$ & $620 \mathrm{MPa}$ \\
$G_{r t, O}$ & $24 \mathrm{MPa}$ \\
$v_{l r}$ & 0.38 \\
$v_{l t}$ & 0.51 \\
$v_{r t}$ & 0.51 \\
\hline
\end{tabular}

not actually achieved until this part of the calculation process is performed.

\section{Definition and assessment of indicating properties}

Below, novel IPs are defined on the basis of the cross sectional stiffness profiles calculated as described above. However, in order to evaluate the competitiveness of those IPs, comparisons must be made with IPs that are commonly employed in grading methods of today or within research. Thus also IPs to be employed for comparisons are defined below.

\subsection{Common IPs to be used for comparison}

In EN 408 it is defined how to determine a local MOE and a global MOE, denoted $E_{m}$ and $E_{m, g}$, respectively, using four point bending tests. The local MOE is calculated on the basis of the local deflection measured within the constant moment zone and over a distance of five times the depth of the board, here $725 \mathrm{~mm}$ containing what is supposed to be the weakest part of the board. The global MOE is based on the mid-span deflection of the board. A thorough definition of $E_{m}$ and $E_{m, g}$ is also given by Olsson et al. (2011).

In addition to $E_{m}$ and $E_{m, g}$, the dynamic MOE calculated on the basis of the resonance frequency corresponding to the first longitudinal mode of vibration, i.e. $E_{a 1}$ according to Eq. (14), and the average board density, $\rho$, are used as comparative IPs in the result section below.

\subsection{Novel IPs based on board stiffness profiles on cross-sectional level}

The MOE defined by the lowest edgewise bending stiffness along the board, calculated using Eq. (11) and with calibration according to Eq. (16), can be expressed (if edgewise bending is bending around the $y$-axis) as
$E_{b, \min }=\min _{0 \leq x \leq L}\left(E I_{y}(x)\right) / I_{y 0}$

where $I_{y 0}=t d^{3} / 12$. The bending stiffness $E_{b, \text { min }}$ is here evaluated as a possible IP to bending strength. It should be noted that the employed spatial resolution when calculating $E I_{y}(x)$ is very high, the bending stiffness being assessed every $0.8 \mathrm{~mm}$ along the board, and it is likely that an average stiffness value over a certain distance, $\delta$, along the board, would give a better IP to bending strength. Therefore a more general expression for possible IPs is defined as

$E_{b, \min , \delta}=\min _{\delta / 2 \leq \bar{x} \leq L-\delta / 2}\left(\frac{1}{\delta} \int_{x=\bar{x}-\delta / 2}^{\bar{x}+\delta / 2} E I_{y}(x) d x\right) / I_{y 0}$

Considering the fact that large knots or groups of knots in spruce have an extension of typically $60-100 \mathrm{~mm}$ it is reasonable to assume that the average bending stiffness over such a distance can give a suitable IP to bending strength. Therefore $E_{b, \min , 60}, E_{b, \min , 80}$ and $E_{b, \min , 100}$, i.e. IPs defined according to Eq. (18) with $\delta=60,80$ and $100 \mathrm{~mm}$, respectively, have been assessed.

The stiffness profile gives information not only about the lowest stiffness value and the extension of the weak zones in the longitudinal direction of the board but also about their position, see the graphs shown in Fig. 6. Furthermore, structural timber is rarely exposed to large bending moments close to the ends and in a four point bending test, carried out in accordance with EN 408, only a distance of six times the depth of the board is exposed to the maximum bending moment. In any case, the parts of the boards closer to the ends than about $7 d$ cannot be exposed to maximum bending moment when assessed according to the standard. Therefore it is reasonable to evaluate an IP defined as

$E_{b, \min , \delta, w}=\min _{d+\delta / 2 \leq \bar{x} \leq L-d-\delta / 2}\left(\frac{1}{\delta} \int_{x=\bar{x}-\delta / 2}^{\bar{x}+\delta / 2} E I_{y}(x) \cdot w(x) d x\right) / I_{y 0}$

where the weight function $w(x)$ is defined as

$w(x)=\left\{\begin{array}{cc}6 \mathrm{~d} /(x-d), & d<x<7 d \\ 1, & 7 d \leq x \leq L-7 d \\ 6 \mathrm{~d} /(L-d-x), & L-7 d<x<L-d\end{array}\right.$

This gives a weighting of the stiffness profile in correspondence with a load case were the bending moment distribution is such that no bending occurs at a distance $d$ from each end of the beam, a linear increase in bending moment then occurs from $d$ to $7 d$ from each end and a constant, maximum bending moment occurs in the middle part of the beam. 
Though it can be expected that the calculated cross sectional stiffness profile $E A(x)$ is less useful for defining efficient IPs to bending strength than what $E I_{y}(x)$ is, it may be interesting for comparison to evaluate how well the bending strength may be predicted using an IP defined as

$E_{a, \min }=\min _{0 \leq x \leq L}(E A(x)) /(t \times d)$

\section{Results and discussion}

The results and discussion presented below is divided into two parts. In the first, statistical results for the measured and calculated properties defined above, which are of general interest for strength grading purposes, are presented and discussed. In the second part additional results and observations regarding the particular test series comprising 105 boards are presented and discussed. These results give indications regarding the potential for further development of the method.

\subsection{Statistical relations for common board properties and novel IPs to bending strength}

Table 2 shows mean values and standard deviations for the bending strength, the local and global MOE, respectively, the dynamic longitudinal MOE, the board density and the novel IPs defined above. It is observed that the novel IP candidates $E_{b, \min }, E_{b, \min , 80}, E_{b, \min , 80, w}$ and $E_{a, \min }$ are considerably lower than the mean values for $E_{m}, E_{m, g}$, and $E_{a 1}$. For the lowest MOE calculated for a section along a beam, $E_{b, \min }$, the mean value is as low as $7.1 \mathrm{GPa}$, i.e. only $57 \%$ of the mean value of $E_{a 1}$. The mean value of $E_{b, \min , 80}$ is $9.4 \mathrm{MPa}$, i.e. $76 \%$ of the mean value of $E_{a 1}$. This gives an indication of how much lower the bending stiffness is on a local level compared to the average board stiffness.

Table 3 shows coefficients of determination between the same properties as those included in Table 2. Of particular interest are the coefficients of determination between IPs and bending strength (printed in bold face in Table 3). The axial dynamic stiffness $E_{a l}$ is often used as an IP in commercial grading and for the boards assessed here it gives a coefficient of determination to the bending strength of 0.59 . The IP $E_{b, \min }$ gives a better result, $\mathrm{R}^{2}=0.64$, but an additional improvement was reached using the minimum bending stiffness over a distance of $80 \mathrm{~mm}$, rather than using the lowest value in a single section of the beam. For $E_{b, \min , 80}$ the coefficient of determination to bending strength was 0.68 . Attempts were made for shorter and longer distances, i.e. with other values of $\delta$ in $E_{b, \min , \delta, w}$, but $80 \mathrm{~mm}$ gave the highest coefficient of determination. By considering that the outer parts of the boards, closer to the ends than $7 d$ cannot be subjected to maximum bending moment in a test according to EN 408, the correlation between the IP and the bending strength was even further improved. $E_{b, \min , 80, w}$ gave a coefficient of determination as high as 0.71 . In practical grading, $E_{b, m i n, 80, w}$ should not be used as an IP as parts from different boards may be joined together by a finger joint and a weak part close to the end of one original graded board may end up in a critical position of an assembled board, but it is presented herein in order to illustrate the ability of the suggested method. In practise, $E_{b, \min , 80}$ is a more suitable IP. Figure 7 shows scatter plots, coefficients of determination and equations for regression lines between $E_{a l}$, and $\sigma_{m}$ and between $E_{b, \min , 80, w}$ and $\sigma_{m}$, respectively.

\subsection{Additional results and observations}

For the 105 boards investigated the part of each board including the worst defect, i.e. the knot or group of knots that was supposed to cause failure, was if possible positioned in the maximum bending moment zone when bending strength was determined according to EN 408. If

Table 2 Mean values and standard deviations for different properties of the 105 boards

Tab. 2 Mittelwerte und Standardabweichungen verschiedener Eigenschaften der 105 Bretter

\begin{tabular}{lll}
\hline & Mean value & SD \\
\hline$\sigma_{m}$ & $38.4 \mathrm{MPa}$ & $12.9 \mathrm{MPa}$ \\
$E_{m}$ & $11.0 \mathrm{GPa}$ & $2.8 \mathrm{GPa}$ \\
$E_{m, g}$ & $10.6 \mathrm{GPa}$ & $2.3 \mathrm{GPa}$ \\
$E_{a 1}$ & $12.4 \mathrm{GPa}$ & $2.6 \mathrm{GPa}$ \\
$\rho$ & $472 \mathrm{~kg} / \mathrm{m}^{3}$ & $52 \mathrm{~kg} / \mathrm{m}^{3}$ \\
$E_{b, \min }$ & $7.1 \mathrm{GPa}$ & $2.7 \mathrm{GPa}$ \\
$E_{b, \min , 80}$ & $9.4 \mathrm{GPa}$ & $2.9 \mathrm{GPa}$ \\
$E_{b, \min , 80, w}$ & $9.7 \mathrm{GPa}$ & $2.9 \mathrm{GPa}$ \\
$E_{a, \text { min }}$ & $8.4 \mathrm{GPa}$ & $2.5 \mathrm{GPa}$ \\
\hline
\end{tabular}

Table 3 Coefficients of determination, $\mathrm{R}^{2}$, between different properties of the 105 boards

Tab. 3 Bestimmtheitsmaße $\mathrm{R}^{2}$ für die Beziehung zwischen verschiedenen Materialeigenschaften der 105 Bretter

\begin{tabular}{llllllll}
\hline$R^{2}$ & $\sigma_{m}$ & $E_{a 1}$ & $\rho$ & $E_{b, \min }$ & $E_{b, \min , 80}$ & $E_{b, \min , 80, w}$ & $E_{a, \min }$ \\
\hline$\sigma_{m}$ & 1 & $\mathbf{0 . 5 9}$ & $\mathbf{0 . 2 7}$ & $\mathbf{0 . 6 4}$ & $\mathbf{0 . 6 8}$ & $\mathbf{0 . 7 1}$ & $\mathbf{0 . 6 1}$ \\
$E_{a 1}$ & $\mathbf{0 . 5 9}$ & 1 & 0.65 & 0.80 & 0.89 & 0.88 & 0.88 \\
$\rho$ & $\mathbf{0 . 2 7}$ & 0.65 & 1 & 0.41 & 0.47 & 0.43 & 0.49 \\
$E_{b, \min }$ & $\mathbf{0 . 6 4}$ & 0.80 & 0.41 & 1 & 0.95 & 0.92 & 0.90 \\
$E_{b, \text { min }, 80}$ & $\mathbf{0 . 6 8}$ & 0.89 & 0.47 & 0.95 & 1 & 0.97 & 0.92 \\
$E_{b, \text { min }, 80, w}$ & $\mathbf{0 . 7 1}$ & 0.88 & 0.43 & 0.92 & 0.97 & 1 & 0.90 \\
$E_{a, \text { min }}$ & $\mathbf{0 . 6 1}$ & 0.88 & 0.49 & 0.90 & 0.92 & 0.90 & 1 \\
\hline
\end{tabular}

Bold values indicate coefficients of determination between bending strength and other properties are particularly interesting 
Fig. 7 Scatter plots, coefficients of determination and equations for the regression lines between (left) $E_{a l}$ and $\sigma_{m}$ and (right) $E_{b, \min , 80, w}$ and $\sigma_{m}$ Abb. 7 Streudiagramme, Bestimmtheitsmaße und Gleichungen der Regressionsgeraden zwischen (links) $\mathrm{E}_{\mathrm{a} 1}$ und $\sigma_{\mathrm{m}}$ sowie (rechts) $\mathrm{E}_{\mathrm{b}, \mathrm{min}, 80, \mathrm{w}}$ und $\sigma_{\mathrm{m}}$

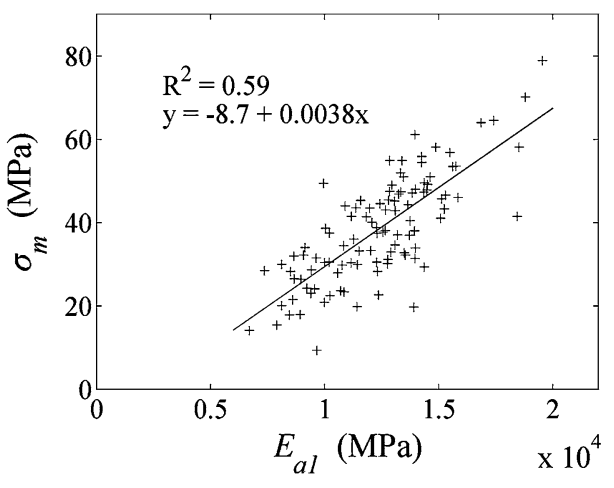

this part was so close to the end that it could not be positioned within this zone the second worst defect was placed in the maximum bending moment zone and so on. For all the boards it was documented where the supports and point loads were positioned and thereby it is known what part of each board that was subjected to maximum bending moment. Furthermore, for each board the location of the failure initialization was documented, although in some cases it was difficult to identify this position accurately in the broken board.

With knowledge regarding how each board was positioned in the testing machine and with a calculated bending stiffness profile for each individual board, it was possible to establish a finite element (FE) model for the part of each board that was actually subjected to bending and to simulate the load case of four point bending. The FE model employed here consists of a series of beam elements, each approximately $2 \mathrm{~cm}$ long. On the basis of the displacements obtained in the FE-calculation, MOEs, here denoted $E_{m, c}$ and $E_{m, g, c}$, respectively, were then calculated in analogy with $E_{m}$ and $E_{m, g}$ obtained from the measured deflections during testing. Table 4 shows coefficients of determination between these different MOEs, based on measurements during testing and based on FE-calculations, respectively, but representing the same timber, i.e. the same $18 d=2,610 \mathrm{~mm}$ long parts of the boards in four point bending. The coefficients of determination between these MOEs and the bending strength are also shown in Table 4. The MOEs based on measured deflections, $E_{m}$ and $E_{m, g}$, correlate considerably better with the bending strength $\left(R^{2}=0.74\right.$ and 0.72 respectively) than what the MOEs based on calculated deflections, $E_{m, c}$ and $E_{m, g, c}$, do ( $R^{2}=0.61$ for both cases). There is, however, a rather strong correlation between MOEs based on measured and calculated deflections, the coefficients of determination being 0.85 both between $E_{m}$ and $E_{m, c}$ and between $E_{m, g}$ and $E_{m, g, c}$.

As both MOEs based on measured and calculated deflections represent the same physical parts of the timber, any differences between $E_{m}$ and $E_{m, c}$, or between $E_{m, g}$ and
Table 4 Coefficients of determination, $R^{2}$, between bending strength and MOEs based on measurements and calculations, respectively

Tab. 4 Bestimmtheitsmaße $\mathrm{R}^{2}$ für die Beziehung zwischen Biegefestigkeit und E-Modul basierend auf Messungen und Berechnungen

\begin{tabular}{llllll}
\hline $\mathrm{R}^{2}$ & $\sigma_{m}$ & $E_{m}$ & $E_{m, g}$ & $E_{m, c}$ & $E_{m, g, c}$ \\
\hline$\sigma_{m}$ & 1 & $\mathbf{0 . 7 4}$ & $\mathbf{0 . 7 2}$ & $\mathbf{0 . 6 1}$ & $\mathbf{0 . 6 1}$ \\
$E_{m}$ & $\mathbf{0 . 7 4}$ & 1 & 0.92 & 0.85 & 0.85 \\
$E_{m, g}$ & $\mathbf{0 . 7 2}$ & 0.92 & 1 & 0.89 & 0.91 \\
$E_{m, c}$ & $\mathbf{0 . 6 1}$ & 0.85 & 0.89 & 1 & 0.99 \\
$E_{m, g, c}$ & $\mathbf{0 . 6 1}$ & 0.85 & 0.91 & 0.99 & 1 \\
\hline
\end{tabular}

Bold values indicate coefficients of determination between bending strength and other properties are particularly interesting

$E_{m, g, c}$, reveals a certain lack of precision when trying to calculate the true bending stiffness profile on the basis of projected fibre angles, employed integration scheme and longitudinal dynamic excitation. The suggested approach seems to be accurate enough to give a very good correlation between suggested IPs and bending strength, but the results presented in Table 4 indicate that there is a considerable potential to improve the correlation further. If the high resolution of the bending stiffness profiles (which can be calculated rapidly on the basis of results from scanning) can reach the accuracy of the measured edgewise bending stiffness (i.e. measured on a more or less global level during four-point bending) it is likely that a coefficient of determination between a single IP and the bending strength may approach or even exceed $R^{2}=0.80$. To what degree the present differences between $E_{m}$ and $E_{m, c}$, and between $E_{m, g}$ and $E_{m, g, c}$ depend (1) on the fact that projected fibre angles on surfaces are utilized rather than the true, three dimensional fibre angle field within the wooden member, (2) on the simplifying assumption that the wood material parameters relating to the 1-r-t system are constant within a wooden member, (3) on the assumption that the stiffness can be captured accurately enough using a beam model, or on some other conditions should be investigated through further research.

A final observation concerns the position along each beam where failure actually was initialized in relation to 
where it was expected to occur, i.e. where the calculated bending stiffness was at its lowest in relation to the applied bending moment. In $70 \%$ of the boards the distance between the actual position of failure and the predicted position was less than $5 \mathrm{~cm}$ and for $78 \%$ of the boards the distance was less than $10 \mathrm{~cm}$. This indicates a high probability for failure to take place within a close surrounding of the section with the lowest bending stiffness. It may be noted, however, that many boards have a second weak section, and maybe even a third, with calculated bending stiffness almost as low as the weakest one.

\section{Conclusion}

High resolution information regarding local fibre orientation on face and edge surfaces of wooden boards can nowadays be sampled in a speed corresponding to the production speed at a sawmill. By utilizing such information in order to calculate the variation in bending stiffness along an individual board very accurate indicating properties with respect to bending strength can be defined. However, information regarding basic wood material properties, in particular MOE in the fibre direction, needs to be available for each individual board. One way to obtain such information is to measure the first longitudinal resonance frequency and the board density which in combination with fibre orientation information can be used to calculate an average MOE in the fibre direction.

For a sample consisting of 105 spruce boards of dimension $45 \times 145 \times 3,600 \mathrm{~mm}^{3}$ it is shown that an IP defined as the edgewise bending stiffness of the weakest (least stiff) $80 \mathrm{~mm}$ part along each board gave a coefficient of determination to bending strength of 0.68. If it is considered that sections close to the ends of the boards cannot be subjected to large bending moments when tested the coefficient of determination increases to 0.71 . For the same boards the coefficient of determination between global MOE based on the first resonance frequency and the board density is only 0.59 .

The theory of how the local stiffness in the direction of a board can be calculated on the basis of basic wood parameters and three dimensional fibre directions is presented independently of the simplifying assumptions that need to be introduced when actually calculating the stiffness profiles, indicating properties and coefficients of determination. It is also shown that higher accuracy when determining these properties, i.e. if errors originating from simplifying assumptions can be avoided, an even stronger correlation would be achieved between a local bending stiffness and bending strength. Thus, along with the development of commercial grading procedures on the basis of the research results already presented herein, further development towards even more accurate calculations of bending stiffness profiles of boards is encouraged.

To obtain optimum IPs, the distance $\delta$ over which the average bending stiffness is calculated may depend on the dimensions of the wooden boards assessed. Some tests and calculations performed on batches of timber of other dimensions than $45 \times 145 \mathrm{~mm}^{2}$ suggest that a distance of about half the depth of the timber member (rather than a constant distance of $80 \mathrm{~mm}$ ) would give a suitable IP, but further tests and calculations on different dimensions of wooden boards need to be carried out in order to confirm this.

Finally, it should be noted that the calculated stiffness profiles could also be of use in a material efficient production of engineered wood products where the significance of weak sections may depend on their location or when it is suitable to eliminate weak sections before assembling.

Open Access This article is distributed under the terms of the Creative Commons Attribution License which permits any use, distribution, and reproduction in any medium, provided the original author(s) and the source are credited.

\section{References}

Bechtel FK, Allen JR (1987) Methods of implementing grain angle measurements in the machine stress rating process. In: 6th Nondestructive testing of wood symposium, Sept 1987, Washington State University, Pullman

Brookhuis Micro-Electronics BV (2009) Timber grader MTGoperating Instructions. MTG Manual GB 12062009-C

CEN (2009) EN 14081-4 Timber structures: strength graded structural timber with rectangular cross section, Part 4: machine gradingGrading machine settings for machine controlled systems

CEN (2010a) EN 384 Structural timber: determination of characteristic values of mechanical properties and density. European Committee for Standardization, CEN/TC124

CEN (2010b) EN 408 Timber structures: structural timber and glued laminated timber-determination of some physical and mechanical properties. European Committee for Standardization, CEN/ TC124

Dinwoodie JM (2000) Timber: Its nature and behaviour. E \& FN Spon, New Fetter Lane, London

Jehl A, Bléron L, Meriaudeau F, Collet R (2011) Contribution of Slope of Grain Information in Lumber Strength Grading. In: 17th international nondestructive testing and evaluation of wood symposium, Sept 2011, University of West Hungary, Sopron

Johansson C-J (2003) Grading of timber with respect to mechanical properties. In: Thelandersson S, Larsen HJ (eds) Timber engineering. Wiley, Chichester, UK

Larsson D (1997) Mechanical Characterization of Engineering Materials by Modal Testing. Doctoral thesis, Chalmers University of Technology, Gothenburg

Moore HE, Baldwin RD (2011) Structural grading of lumber using grain angle in a production environment. In: 17th International nondestructive testing and evaluation of wood symposium, Sept 2011, University of West Hungary, Sopron 
Nyström J (2003) Automatic measurement of fiber orientation in softwoods by using the tracheid effect. Computers and Electronics in Agriculture, 41(1):91-99

Olsson A, Oscarsson J, Johansson M, Källsner B (2011) Prediction of timber bending strength on basis of bending stiffness and material homogeneity assessed from dynamic excitation. Wood Sci Technol 46(4):667-683

Ormarsson S (1999) Numerical analysis of moisture-related distorsions in sawn timber. Doctoral thesis, Chalmers University of Technology, Gothenburg

Petersson H (2010) Use of optical and laser scanning techniques as tools for obtaining improved fe-input data for strength and shape stability analysis of wood and timber. IV European Conference on Computational Mechanics, May 2010, Paris

Schajer GS (2001) Lumber strength grading using x-ray scanning, Forest Products Journal 51(1), 43-50

Wormuth E-W (1993) Study of the relation between flatwise and edgewise modulus of elasticity of sawn timber for the purpose of improving mechanical stress methods. Diploma work, University of Hamburg, Hamburg 